\title{
The effects of GH and hormone replacement therapy on serum concentrations of mannan-binding lectin, surfactant protein $D$ and vitamin $D$ binding protein in Turner syndrome
}

\author{
Claus Højbjerg Gravholt ${ }^{1}$, Rikke Leth-Larsen ${ }^{2}$, Anna Lis Lauridsen ${ }^{3}$, Steffen Thiel ${ }^{4}$, Troels Krarup Hansen ${ }^{1}$, \\ Uffe Holmskov $^{2}$, Rune Weis Naeraa ${ }^{5}$ and Jens Sandahl Christiansen ${ }^{1}$ \\ ${ }^{1}$ Medical Department M (Endocrinology and Diabetes) and Medical Research Laboratories, Århus Kommunehospital, Århus University Hospital, \\ 8000 Århus C, Denmark, ${ }^{2}$ Department of Immunology and Microbiology, Institute of Medical Biology, University of Southern Denmark, 5000 Odense C, \\ Denmark, ${ }^{3}$ Department of Clinical Chemistry, Århus Kommunehospital, Århus University Hospital, 8000 Århus C, Denmark, ${ }^{4}$ Department of Medical \\ Microbiology and Immunology, University of Århus, 8000 Århus C, Denmark and ${ }^{5}$ Department of Pediatrics, Randers Centralsygehus, 8900 Randers, \\ Denmark \\ (Correspondence should be addressed to C H Gravholt; Email: ch.gravholt@dadlnet.dk)
}

\begin{abstract}
Objective: Studies in animals and humans indicate that growth hormone (GH) and insulin-like growth factor-I (IGF-I) modulate immune function. Recently, it was reported that GH therapy increased the level of mannan-binding lectin (MBL) in normal patients, and that treatment of acromegalics with pegvisomant decreased the levels of MBL. The effect on MBL was thought to be due to a specific action of GH, since IGF-I treatment did not affect MBL. Whether it is advantageous or not to have high or low levels of MBL is not known. Likewise, it is not clear how the modifications induced by $\mathrm{GH}$ affect immune function. In the present study we examined whether $\mathrm{GH}$ or hormone replacement therapy (HRT) in Turner syndrome (TS) influence the serum concentrations of MBL and two other proteins partaking in the innate immune defence, surfactant protein D (SP-D) and vitamin D binding protein (DBP).

Design: Study 1: a double-blind crossover study of 12 healthy TS adolescents examined during treatment with either placebo or GH for 2 months, and compared with a control group. Study 2: tripleblind crossover study of 9 healthy TS adolescents randomized to treatment with placebo, GH or $\mathrm{GH}+17 \beta$-estradiol. Study 3: 60 adult TS patients ( 55 received HRT) compared with 59 age-matched controls. Study 4: 27 patients with TS were examined before and during sex hormone replacement with $17 \beta$-estradiol and norethisterone and compared with age-matched controls $(n=24)$. Methods: Measurement of MBL, SP-D, DBP, and other inflammation markers.

Results: Study 1: the levels of MBL $(P=0.002)$ and SP-D $(P=0.012)$ increased during GH treatment, whereas no changes were observed in comparison with controls. DBP was unchanged by $\mathrm{GH}$, but was significantly higher in TS compared with controls $(P=0.017)$. Study 2 : treatment with GH increased MBL $(P=0.045)$ and SP-D $(P=0.05)$ concentrations in TS, while treatment with GH $+17 \beta$-estradiol did not increase levels further. DBP was unchanged by treatment. Study 3: levels of MBL, SP-D, and DBP were similar in adult TS and control subjects. Study 4: DBP levels decreased in response to HRT, while MBL and SPD levels were unchanged. Levels of all three plasma proteins were similar to controls.

Conclusion: We show that treatment with GH significantly increases MBL and SP-D concentrations in TS, while HRT marginally decreases DBP. Whether the present findings, suggesting a link between the endocrine and the immune system, have clinical consequences needs to be studied further.
\end{abstract}

European Journal of Endocrinology 150 355-362

\section{Introduction}

Middle ear infections are extremely frequent in Turner syndrome (TS), occurring in more than $50 \%$ of all patients $(1,2)$. This increased frequency of middle ear infections has been attributed to the congenital craniofacial malformation with possible distortion of the
Eustachian tube and impaired ventilation of the middle ear. In keeping with this, auricular anomalies have been noted, primarily in females with the 45,X karyotype, but in fewer patients than were affected by middle ear infections (3). In addition to middle ear infections, pneumonia (relative risk (RR): 12 (95\% confidence interval (CI): 4-26)) and diseases of the 
respiratory system (RR: 8 (95\% CI: 4-15)) are frequent causes of death in TS in comparison with the background population (4), suggesting a defective immune system leading to increased susceptibility to infections. Most patients with TS have no gonadal function and are thus, if untreated, deficient in female sex steroids from early childhood and onwards. Besides gonadal insufficiency, the cardinal stigmata of TS are growth retardation with reduced final height, and infertility. Furthermore, a number of congenital malformations and conditions are associated with TS (5). Growth hormone (GH) is widely used to increase final height, and, in those girls who do not experience spontaneous puberty, pubertal induction with estradiol and subsequent treatment with hormonal replacement therapy (HRT) is instituted when breakthrough bleeds occur.

Recently, we showed that mannan-binding lectin (MBL) is strongly affected by GH, but not by insulinlike growth factor-I (IGF-I) (6), in normal males given high to very high pharmacological ('doping') doses of GH. Furthermore, it was shown that untreated patients with growth hormone deficiency (GHD) had low levels of MBL that increased in response to $\mathrm{GH}$, and that patients with acromegaly had elevated levels of MBL that decreased in response to octreotide as well as to pegvisomant - the new GH receptor blocking agent. MBL (also known as mannose-binding lectin) is an innate immune defence plasma protein synthesized in the liver. It binds to specific repetitive carbohydrate structures on microbial surfaces, and subsequently activates the complement cascade through MBL-associated serine proteases (MASP-1, MASP-2, and MASP-3) $(7,8)$ - the so-called MBL pathway of complement activation. The concentration of MBL in human plasma is genetically determined. Because of the high frequency of three mutant MBL alleles, as well as mutations in the promoter region of the gene, very large inter-individual differences in MBL concentrations exist and the presence of MBL deficiency among $10 \%$ of the population makes it the most frequent immunodeficiency described (9). Studies indicate that MBL is of importance in first-line immune defence against a number of important pathogens (10-12), and low serum concentrations of MBL are associated with increased susceptibility to recurrent infections (13), although low levels of MBL in healthy individuals may well confer some selective advantage (9). This selective advantage could be due to MBL-mediated complement activation after hypoxia aggravating ischemic injury $(14,15)$, and inhibition of MBL activation of the lectin pathway protects the heart from ischemic lesions (16). Thus, it is not clear how changes in circulating MBL induced by $\mathrm{GH}$ will affect overall immune function, if at all. Recently, it has become clear that surfactant protein (SP)-D and SP-A, also collectins, may be the pulmonary counterparts of MBL; they participate in all aspects of the inflammatory response to pulmonary pathogens and are also located at extrapulmonary mucosal surfaces (17).

The aims of the present study were to examine the levels of MBL and of SP-D and vitamin D binding protein (DBP) in TS; to examine the influence of GH treatment on MBL, SP-D, and DBP levels; and to examine the influence of another pituitary axis, the female sex hormone axis, on the synthesis and control of these proteins, and thus possibly establish another link between the immune and the endocrine system.

\section{Subjects and methods}

\section{Subjects and experimental designs}

We utilized serum from four previous studies from our own department. These studies fulfilled a design enabling us to answer the questions above.

Study 1 We examined twelve girls with TS verified by chromosomal karyotyping in a randomized, placebocontrolled, cross-over design (Table 1), to study the effect of $\mathrm{GH}$ and to compare this with a control group. None of the participants had previously received estrogen. Four of the girls were spontaneously menstruating. Eight had the karyotype $45, \mathrm{X}$, two had $45, \mathrm{X} / 46, \mathrm{XX}$,

Table 1 Demographics of the studies, with details concerning age (median (range)), number of participants, Tanner stage (where applicable), and treatment.

\begin{tabular}{|c|c|c|c|c|c|}
\hline Study & & Age & Number & Tanner stage & Treatment \\
\hline \multirow[t]{2}{*}{1} & Turner syndrome & $13(10-15)$ & 12 & $1: n=7 ; 2: n=2 ; 4: n=3$ & $\mathrm{GH} /$ placebo for 2 months \\
\hline & Controls & $12(10-16)$ & 16 & $\begin{array}{l}1: n=4 ; 2: n=2 ; 3: n=2 \\
\quad 4: n=6,5: n=2\end{array}$ & - \\
\hline 2 & Turner syndrome & $16(13-18)$ & 9 & $1: n=1 ; 3: n=4,4: n=4$ & $\begin{array}{l}\text { GH and } 17 \beta \text {-estradiol, } \\
\text { GH and placebo, placebo } \\
\text { and placebo for } 2 \text { months each }\end{array}$ \\
\hline \multirow[t]{2}{*}{3} & Turner syndrome & $37(22-67)$ & 60 & - & $\begin{array}{l}\text { HRT }(n=53) \text {, no treatment }(n=5) \text {, } \\
\text { spontaneous menstruation }(n=2)\end{array}$ \\
\hline & Controls & $36(22-66)$ & 59 & - & No treatment \\
\hline \multirow[t]{2}{*}{4} & Turner syndrome & $34(21-49)$ & 27 & - & HRT (6 months)/no treatment (4 months) \\
\hline & Controls & $33(21-46)$ & 24 & - & No treatment \\
\hline
\end{tabular}


one had 46,X,i(Xq), and one had 45,X/46,X,i(Xq)/47, $\mathrm{X}, \mathrm{i}(\mathrm{Xq}), \mathrm{i}(\mathrm{Xq})$. At least 5 months prior to inclusion in the study all girls with TS received GH $(0.1 \mathrm{IU} / \mathrm{kg} /$ day $)$. During the study subjects received GH (Norditropin, Novo Nordish, Denmark) $0.1 \mathrm{IU} / \mathrm{kg} /$ day s.c. at bedtime for 2 months, or placebo. The average daily dose was $3.5 \pm 0.9 \mathrm{IU} \mathrm{GH}$ during the study period. An agematched control group $(n=16)$ was studied once. TS girls were studied twice during the end of each treatment period, while controls were studied once. Data from this study regarding the effects of GH on metabolism have previously been reported (18).

Study 2 We examined the effect of GH and estrogen in nine girls with TS verified by chromosomal karyotyping (Table 1), in a randomized, triple-blind, placebo-controlled, crossover study, with 2 -month treatment periods. All of the participants were receiving $\mathrm{GH}$ and estrogen prior to entering the study. Four had the karyotype $45, \mathrm{X}$, one had $45, \mathrm{X} / 46, \mathrm{XX}$, three had structural abnormalities of one $X$ chromosome (2 mosaics), and one had 45,X/46,X,r(Y). At least 5 months prior to inclusion in the study all girls with TS received GH $(3.7 \pm 0.9 \mathrm{IU} /$ day $)$ and $17 \beta$-estradiol $(0.33 \pm 0.16 \mathrm{mg} /$ day $)$. During the study subjects received GH (Norditropin) and 17 $\beta$-estradiol, GH (Norditropin) and placebo, or placebo and placebo, at the same dose as at inclusion. The TS girls were studied thrice during the end of each treatment period.

Study 3 We examined adults with TS, most treated with HRT, and compared them with a control group (Table 1). Sixty patients with TS, diagnosed by chromosome analysis, and 59 age-matched controls were studied. Karyotypes among TS subjects were distributed as follows: 45,X $(n=29), 45, \mathrm{X} / 46, \mathrm{XX}(n=5)$, karyotypes with isochromosomes $(\mathrm{Xq})$ or deletions $(n=16)$, karyotypes with $\mathrm{Y}$ chromosome material $(n=5)$, karyotypes with a marker or ring chromosome $(n=5)$. Treatment consisted of $17 \beta$-estradiol $(2 \mathrm{mg})$ for the entire cycle and norethisterone $(1 \mathrm{mg})$, medroxyprogesterone $(10 \mathrm{mg})$ or levonorgestrel $(0.25 \mathrm{mg})$ for 10 days every cycle. The average duration of HRT was $16 \pm 9$ years, and the age at start of HRT was $21 \pm 10$ (range: 9-60) years. Data from this study regarding bone metabolism have previously been reported (19).

Study 4 To further study the effect of HRT versus no treatment, 27 TS patients and an age-matched control group of 24 normal women (all premenopausal) with presumed normal karyotype were studied (Table 1). Karyotypes among TS patients were distributed as follows: 45,X $(n=17), 45, \mathrm{X} / 46, \mathrm{XX}(n=1)$, karyotypes with isochromosomes $(\mathrm{Xq})$ or deletions $(n=7)$, karyotypes with $\mathrm{Y}$ chromosome material $(n=2)$. All TS patients were receiving female hormone replacement therapy, but prior to the initial examination (basal examination, TB) a 4-month washout period was introduced. None of the TS patients had experienced spontaneous puberty. Following the initial examination, patients were randomized to two regimens of hormone substitution (treatment period, TT): oral hormone replacement consisting of $2 \mathrm{mg} 17 \beta$-estradiol/day from days 1 to $12,2 \mathrm{mg} 17 \beta$-estradiol/day and $1 \mathrm{mg}$ norethisterone acetate/day from days 13 to 22 and $1 \mathrm{mg} 17 \beta$-estradiol/day from days 23 to 28 (Trisekvens, Novo Nordisk, Bagsvaerd, Denmark), or transdermal estrogen replacement consisting of approximately $50 \mu \mathrm{g} 17 \beta$-estradiol $/ 55 \mathrm{~kg} /$ day for 28 days (Estraderm, Ciba-Geigy, Copenhagen, Denmark) and $1 \mathrm{mg}$ norethisterone (Noretisterone Dak, Nycomed DAK, Copenhagen, Denmark) administered orally from days 13 to 22. Fifteen subjects were randomly allocated to the group receiving transdermal estrogen and twelve subjects to the group receiving oral estrogens. Within the first month of treatment, three subjects from the group receiving transdermal estrogens had to be transferred to oral treatment due to irritative dermatitis. These three subjects were thus transferred to oral treatment and subsequently included as such in the statistical analysis. Preliminary analysis showed no difference in the level of the studied variables, and the two groups were merged for all calculations. All patients were then studied again after 6-months treatment, whereas all controls were examined once. Control subjects and TS patients during sex hormone treatment were studied in the early follicular stage (days 5 to 10) of the menstrual cycle. Data from this study regarding glucose metabolism and GH dynamics have previously been reported $(20,21)$.

All blood samples were collected following an overnight fast. The local ethics committees approved the protocols (\#1991/2031, \#1991/2030, \#1993/2837. \# 1994/2929) and all subjects gave written consent to participate.

\section{Analytical methods}

Serum MBL concentrations were measured using an inhouse time-resolved monoclonal immunofluorometric assay (TRIFMA) as previously described (16). SP-D was measured by a sandwich ELISA technique as previously described (22). DBP was measured by an immunonephelometric assay (23). Serum concentrations of C-reactive protein (CRP) were measured by an ultrasensitive latex-enhanced immunoturbidimetric method, haptoglobin and transferrin by an immunoturbidimetric method, all on a Cobas Integra 700 (Hoffmann-La Roche Ltd, Basel, Switzerland).

\section{Statistics}

Statistical calculations were carried out with SPSS for Windows version 11.0 (SPSS, Chicago, IL, USA). When comparing MBL, SP-D, and CRP levels, Wilcoxon's 
signed rank test or Friedman test for within group comparisons, or Mann-Whitney's U test for between groups comparisons were employed, while parametric statistics (paired, unpaired $t$-test, and one-way ANOVA) were used for the other variables. Spearman correlation was used to examine the relationships among different variables at baseline and following treatment. All results are expressed as median and range (non-parametrically distributed data), or means \pm S.D. (parametrically distributed data). $P$ values $<0.05$ were considered significant.

\section{Results}

\section{Effects of GH treatment on measures of the innate immune system in girls with TS (study 1)}

During $\mathrm{GH}$ treatment for 2 months levels of MBL increased by $96 \%$, SP-D by $17 \%$, while DBP was unchanged (Table 2). In comparison with controls, similar levels of MBL and SP-D were found, while DBP was increased in TS patients (Table 2). There was no significant correlation between the change in any of the studied parameters following treatment regimens.

The baseline level of CRP was higher, and the level of transferrin was lower in TS patients compared with controls, while haptoglobin was similar amongst the study groups (Table 2). There was no significant change in CRP or haptoglobin, while transferrin increased in response to $\mathrm{GH}$ treatment.

\section{Effects of GH and estrogen treatment on measures of the innate immune system in girls with TS (study 2)}

During GH treatment for 2 months levels of MBL increased by $57 \%$, SP-D by $17 \%$, while DBP was unchanged (Table 2). There was no further change in the levels of MBL, SP-D and DBP after combined treatment with GH and estrogen compared with the effect of $\mathrm{GH}$ alone.

The levels of CRP, haptoglobin, and transferrin were not affected by treatment with $\mathrm{GH}$ alone or $\mathrm{GH}$ and $17 \beta$-estradiol combined.

\section{Measures of the innate immune system in adults with TS (study 3)}

There was no difference in the levels of MBL, SP-D, and DBP among adult TS patients $(n=60)$ and controls $(n=59)$ (Table 3). The level of CRP was increased in TS patients compared with controls, while the levels of haptoglobin and transferrin were comparable to controls. In TS patients MBL and SP-D correlated significantly $(r=0.370, P=0.004)$, but not in controls $(r=0.082, P=0.6)$. There was no significant correlation between DBP and MBL or SP-D in TS patients, while SP-D and DBP correlated significantly and

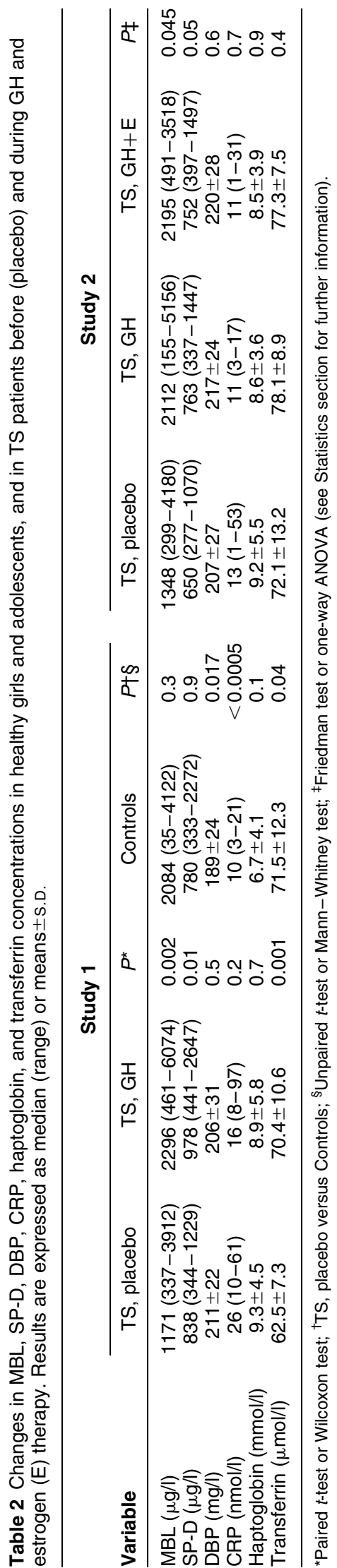

www.eje.org 
inversely in controls $(r=-0.340, P=0.013)$. DBP correlated significantly and positively with CRP $(r=0.335, \quad P=0.009), \quad$ haptoglobin $\quad(r=0.312$, $P=0.015)$ and transferrin $(r=0.258, P=0.047)$ in TS patients, and with transferrin $(r=0.283$, $P=0.044)$ in controls. SP-D also correlated with haptoglobin in TS patients $(r=-0.299, P=0.020)$, but not in controls.

\section{Effects of HRT on measures of the innate immune system in adults with TS (study 4)}

There was no difference in MBL, SP-D, and DBP levels among untreated TS adults and controls (Table 3), and HRT did not change the levels of MBL and SP-D in TS patients, while DBP decreased marginally in response to treatment. There was no difference in CRP, haptoglobin, and transferrin levels among TS patients and controls, although CRP was insignificantly increased in TS patients $(P=0.08)$. Treatment with HRT for 6 months increased the level of transferrin, while levels of CRP and haptoglobin were comparable in the two study situations. The observed changes in haptoglobin correlated significantly with changes in MBL $\quad(r=0.437, \quad P=0.023), \quad$ CRP $\quad(r=0.673$, $P<0.0005), \quad$ DBP $(r=0.731, \quad P<0.0005)$, and transferrin $(r=0.411, P=0.033)$. The changes in transferrin also correlated with CRP $(r=0.434$, $P=0.024)$ and DBP $(r=0.430, P=0.025)$.

\section{Discussion}

The main result of the present study is the pronounced effect of GH treatment in TS patients on the level of some of the studied proteins of the innate immune system. Previously, we showed that GH affects MBL in healthy subjects and GHD patients. Here, we have extended these data to girls and adolescents with TS, and in addition we have shown that two other components of the innate immune system, SD-P and DBP, are also affected by GH or estrogen. The results suggest that synthesis of MBL, SD-P and DBP, and thus probably control of the level of these proteins, are normal in TS patients. However, we confirm a pronounced effect of GH on MBL and on SP-D levels, but no effect on the level of DBP. Thus, there seems to be a link between the endocrine and the innate immune systems. The serum half-life of injected MBL is 5-7 days (24), while the half-life of SP-D is unknown, and it is therefore likely that the increase in MBL, at least, is due to increased synthesis and not decreased degradation. The participants of the study were not tested for MBL gene mutations, but it is known that subjects with gene mutations in the MBL allele or in the promoter region of the gene have MBL levels in another magnitude than those with normal MBL genes (typically $5-50$ versus $500-5000 \mu \mathrm{g} / \mathrm{l})(25)$, and an indirect estimate of the frequency of gene mutations based on the MBL concentrations at baseline suggests that $10 \%$ in all groups had gene mutations.

A number of studies have shown minor deficiencies of humoral and cellular immunity (26-32), and a recent study showed increased apoptosis mediated by the tumor necrosis factor receptor and CD95 in cord blood T-cells (33). Furthermore, Turner syndrome is associated with increased susceptibility to bacterial infections, also a cause of death $(1-4)$, but as the results from the present study show three proteins partaking in the innate immune defence, MBL, SP-D and DBP, are essentially present in amounts comparable to the levels in age-matched controls. However, even though the levels of MBL and SP-D were normal, they increased in response to $\mathrm{GH}$ treatment. Whether this has clinical implications is difficult to say. SP-D (and MBL) is a member of the collectins, being produced by the alveolar type II cells and nonciliated bronchiolar cells and secreted into the alveolar lining layer, and was originally thought to have only surfactant function in the lungs (17). Interestingly, a recent study showed the presence of SP-D (and SP-A) in the epithelial cells of the porcine Eustachian tube (34), suggesting that they partake in the immune defence during middle ear infections. In view of the grossly increased risk of recurrent middle ear infections in TS patients, this finding could be of special importance. However, a recent trial of GH treatment in TS, with an 18-month placebo-controlled age-matched TS group, showed that

Table 3 Changes in MBL, SP-D, DBP, CRP, haptoglobin, and transferrin concentrations in healthy adults, and in TS patients before (placebo) and during HRT. Results are expressed as median (range) or means \pm S.D.

\begin{tabular}{|c|c|c|c|c|c|c|c|c|}
\hline \multirow[b]{2}{*}{ Variable } & \multicolumn{3}{|c|}{ Study 3} & \multicolumn{5}{|c|}{ Study 4} \\
\hline & TS & Controls & $P^{*}$ & TS, placebo & TS, HRT & $P+$ & Controls & $P \ddagger$ \\
\hline $\operatorname{MBL}(\mu \mathrm{g} / \mathrm{l})$ & $1010(13-3314)$ & $1118(23-3311)$ & 0.3 & 695 (12-3677) & $849(6-3894)$ & 0.5 & $992(36-3546)$ & 0.7 \\
\hline SP-D $(\mu g / l)$ & $860(250-1816)$ & 887 (308-2092) & 0.6 & 608 (139-1589) & $579(153-1078)$ & 0.7 & 647 (188-1665) & 0.7 \\
\hline $\mathrm{DBP}(\mathrm{mg} / \mathrm{l})$ & $249 \pm 40$ & $260 \pm 46$ & 0.2 & $219 \pm 25$ & $210 \pm 23$ & 0.04 & $207 \pm 23$ & 0.08 \\
\hline $\mathrm{CRP}(\mathrm{nmol} / \mathrm{l})$ & $27(4-262)$ & $11(2-216)$ & $<0.0005$ & $18(6-146)$ & $23(7-221)$ & 0.2 & $12(7-191)$ & 0.08 \\
\hline Haptoglobin $(\mathrm{mmol} / \mathrm{l})$ & $13.8 \pm 6.0$ & $13.0 \pm 4.6$ & 0.4 & $13.3 \pm 6.2$ & $15.0 \pm 6.2$ & 0.2 & $13.7 \pm 5.5$ & 0.9 \\
\hline Transferrin $(\mu \mathrm{mol} / \mathrm{l})$ & $74.0 \pm 11.2$ & $74.3 \pm 10.7$ & 0.9 & $68.6 \pm 11.2$ & $71.5 \pm 12.8$ & 0.02 & $71.3 \pm 8.3$ & 0.3 \\
\hline
\end{tabular}

*Unpaired $t$-test or Mann-Whitney test; ${ }^{\dagger}$ Paired $t$-test or Wilcoxon test; ${ }^{\ddagger} \mathrm{TS}$, placebo versus Controls. 
otitis media was actually more frequent in the GH-treated group (35). GH is known to mediate water retention, and it is possible that this effect could worsen the unfavorable anatomical conditions present in the middle ear and lead to increased frequency of otitis media. Previously, GH given to acutely ill patients in intensive care approximately doubled the fatality rate (36), the reason for which has not been found. To date, it is not clear whether it is advantageous to have a high or a low level of MBL and SP-D. In another study of acutely ill patients in an intensive care unit treated either conventionally or with high dose insulin, high levels of MBL at baseline in conventionally treated patients was associated with better survival (37). The trial also showed lower levels of MBL in the insulintreated group during the course of intensive care unit stay (37), which also had a highly significant reduction in morbidity and mortality (38). Thus, our finding of a GH-induced increase in MBL and SP-D and the above mentioned increased risk of middle ear infection during GH treatment could be linked, but further research will be necessary to establish such an association. The results from the present GH treatment studies must, of course, be viewed with caution because of the relatively few participants. DBP was not influenced by GH treatment, but decreased slightly in response to HRT (study 4), while baseline levels were comparable to controls. The vitamin D-binding protein is a multifunctional protein produced constitutively by the liver. It serves as a carrier protein for vitamin D, regulating its function thereof by delivering vitamin $\mathrm{D}$ metabolites, including $1,25-(\mathrm{OH})_{2}-\mathrm{D} 3$, to the cells, acts as an actin scavenger with subsequent activation of macrophages, and, in addition, it partakes in the inflammatory response $(39,40)$. It is a co-chemotaxin specific for the complement $\mathrm{C} 5 \mathrm{a}$ and $\mathrm{C} 5 \mathrm{a}-\mathrm{es}-\mathrm{Arg}$ and binds endotoxin (41). After removal of its galactose and sialic acid residues, DBP is converted to a very potent macrophage-activating factor (42). The mechanisms behind its immunomodulatory effects are elusive. Whether the slight decrease in DBP in response to HRT has any clinical significance is doubtful, but it is interesting that another endocrine mediator, $17 \beta$ estradiol (or possibly norethisterone), influences the immune system. Previously, the treatment of normal women with ethinylestradiol has been shown to increase DBP (43), and it remains to be seen whether the discordant results are due to different formulations of estrogen.

In order to study the effect of GH and HRT on other proteins involved in the acute phase response to inflammation, we found that the levels of CRP were increased in TS patients compared with controls, but they were unchanged in response to both GH and HRT. Previously, $\mathrm{GH}$ treatment to GHD patients has been shown to decrease the (previously increased) levels of CRP (6). The levels of haptoglobin, another acute phase protein, were similar in TS patients and in controls, and likewise the levels of the constitutive hepatic protein, transferrin, were similar to the levels in controls, except in study 1 where the levels were slightly decreased, and increased in response to GH, as seen previously (44).

Interestingly, in adults with TS, circulating levels of MBL and SP-D were correlated, while this was not the case in controls. On the contrary, SP-D and DBP were negatively correlated in controls, while not in TS patients. Furthermore, correlations were seen between DBP and SP-D and more traditional markers of inflammation (CRP, haptoglobin, and transferrin). In TS patients during HRT (study 4) changes in MBL and DBP in comparison with the washout phase were also correlated with the more traditional markers of inflammation. These results indicate that even the small changes in these markers observed here are all images of the current state of the immune system.

In summary, GH and HRT in Turner syndrome influence the immune system, as evidenced from increases in MBL and SP-D levels in response to GH treatment, and decreases in DBP levels during HRT. The endocrine and immune systems are interlinked, but whether this has positive or negative consequences remains to be resolved.

\section{Acknowledgements}

Lone Svendsen, Ellinor Hansen and Vivi Møller are thanked for expert technical help. Dr Kim Brixen is thanked for help with compiling some of the normal material. C H G is supported by a research fellowship from the University of Arhus. The study was supported by a grant from the Danish Health Research Council, grant number 9600822 (Århus UniversityNovo Nordisk Center for Research in Growth and Regeneration).

\section{References}

1 Anderson H, Filipsson R, Fluur E, Koch B, Lindsten J \& Wedenberg E. Hearing impairment in Turner's syndrome. Acta Otolaryngologic 1969 (Suppl 247) 1-26.

2 Lippe B. Turner syndrome. Endocrinology and Metabolism Clinics of North America $199120121-152$.

3 Stenberg AE, Nylen O, Windh M \& Hultcrantz M. Otological problems in children with Turner's syndrome. Hearing Research 1998 $12485-90$.

4 Swerdlow AJ, Hermon C, Jacobs PA, Alberman E, Beral V, Daker M, Fordyce A \& Youings S. Mortality and cancer incidence in persons with numerical sex chromosome abnormalities: a cohort study. Annals of Human Genetics 200165 177-188.

5 Gravholt $\mathrm{CH}$. Aspects of the treatment of Turner syndrome. Expert Opinion on Pharmacotherapy 20012 1633-1647.

6 Hansen TK, Thiel S, Dall R, Rosenfalck AM, Trainer P, Flyvbjerg A, Jorgensen JO \& Christiansen JS. GH strongly affects serum concentrations of mannan-binding lectin: evidence for a new IGF-I independent immunomodulatory effect of GH. Journal of Clinical Endocrinology and Metabolism 200186 5383-5388.

7 Matsushita M \& Fujita T. Activation of the classical complement pathway by mannose binding protein in association with a novel C1s-like serine protease. Journal of Experimental Medicine $19921761497-1502$. 
8 Thiel S, Vorup-Jensen T, Stover CM, Schwaeble W, Laursen SB, Poulsen K, Willis AC, Eggleton P, Hansen S, Holmskov U, Reid KB \& Jensenius JC. A second serine protease associated with mannan-binding lectin that activates complement. Nature $1997386506-510$.

9 Turner MW. Mannose-binding lectin: the pluripotent molecule of the innate immune system. Immunology Today $1996 \mathbf{1 7}$ 532-540.

10 Neth O, Jack DL, Dodds AW, Holzel H, Klein NJ \& Turner MW. Mannose-binding lectin binds to a range of clinically relevant microorganisms and promotes complement deposition. Infection and Immunity $2000 \mathbf{6 8} 688-693$.

11 Hibberd ML, Sumiya M, Summerfield JA, Booy R \& Levin M. Association of variants of the gene for mannose-binding lectin with susceptibility to meningococcal disease. Meningococcal Research Group. Lancet 1999353 1049-1053.

12 Garred P, Madsen HO, Balslev U, Hofmann B, Pedersen C, Gerstoft J \& Svejgaard A. Susceptibility to HIV infection and progression of AIDS in relation to variant alleles of mannose-binding lectin. Lancet $1997349236-240$.

13 Super M, Thiel S, Lu J, Levinsky RJ \& Turner MW. Association of low levels of mannan binding protein with a common defect of opsonisation. Lancet $198921236-1239$.

14 Collard CD, Lekowski R, Jordan JE, Agah A \& Stahl GL. Complement activation following oxidative stress. Molecular Immunology $199936941-948$.

15 Collard CD, Vakeva A, Morrissey MA, Agah A, Rollins SA, Reenstra WR, Buras JA, Meri S \& Stahl GL. Complement activation after oxidative stress: role of the lectin complement pathway. American Journal of Pathology 2000156 1549-1556.

16 Jordan JE, Montalto MC \& Stahl GL. Inhibition of mannose-binding lectin reduces postischemic myocardial reperfusion injury. Circulation 2001 104 1413-1418.

17 McCormack FX \& Whitsett JA. The pulmonary collectins, SP-A and SP-D, orchestrate innate immunity in the lung. Journal of Clinical Investigation 2002109 707-712.

18 Gravholt CH, Naeraa RW, Brixen K, Kastrup KW, Mosekilde L, Jørgensen JO \& Christiansen JS. Short term growth hormone treatment in girls with Turner syndrome decreases fat mass and insulin sensitivity. A randomized double-blind, placebo-controlled cross-over study. Pediatrics $2002110889-896$.

19 Gravholt CH, Lauridsen AL, Brixen K, Mosekilde L, Heickendorff L \& Christiansen JS. Marked dysproportionality in bone size and mineral, and distinct abnormalities in bone markers and calcitropic hormones in adult Turner syndrome. A cross-sectional study. Journal of Clinical Endocrinology and Metabolism $2002 \mathbf{8 7}$ 2798-2808.

20 Gravholt CH, Naeraa RW, Fisker S \& Christiansen JS. Body composition and physical fitness are major determinants of the growth hormone-IGF axis aberrations in adult Turner syndrome, with important modulations by treatment with 17-beta estradiol. Journal of Clinical Endocrinology and Metabolism $1997 \mathbf{8 2}$ 2570-2577.

21 Gravholt CH, Naeraa RW, Nyholm B, Gerdes U, Christiansen E, Schmitz O \& Christiansen JS. Glucose metabolism, lipid metabolism, and cardiovascular risk factors in adult Turner syndrome: the impact of sex hormone replacement. Diabetes Care 199821 $1062-1070$.

22 Leth-Larsen R, Nordenbaek C, Tornoe I, Moeller V, Schlosser A, Koch C, Teisner B, Junker P \& Holmskov U. Surfactant protein D (SP-D) serum levels in patients with community-acquired pneumonia small star, filled. Clincal Immunology 2003108 29-37.

23 Lauridsen AL, Vestergaard P \& Nexo E. Mean serum concentration of vitamin D-binding protein (Gc globulin) is related to the Gc phenotype in women. Clinical Chemistry 200147 $753-756$.

24 Valdimarsson H, Stefansson M, Vikingsdottir T, Arason GJ, Koch C, Thiel S \& Jensenius JC. Reconstitution of opsonizing activity by infusion of mannan-binding lectin (MBL) to
MBL-deficient humans. Scandinavian Journal of Immunology 1998 48 116-123.

25 Steffensen R, Thiel S, Varming K, Jersild C \& Jensenius JC. Detection of structural gene mutations and promoter polymorphisms in the mannan-binding lectin (MBL) gene by polymerase chain reaction with sequence-specific primers. Journal of Immunology Methods 2000241 33-42.

26 Jensen K, Petersen PH, Nielsen EL, Dahl G \& Nielsen J. Serum immunoglobulin M, G, and A concentration levels in Turner's syndrome compared with normal women and men. Human Genetics $197631329-334$

27 Lorini R, Ugazio AG, Cammareri V, Larizza D, Castellazzi AM, Brugo MA \& Severi F. Immunoglobulin levels, T-cell markers, mitogen responsiveness and thymic hormone activity in Turner's syndrome. Thymus $1983561-66$.

28 Cacciari E, Masi M, Fantini MP, Licastro F, Cicognani A, Pirazzoli P, Villa MP, Specchia F, Forabosco A, Franceschi C \& Martoni L. Serum immunoglobulins and lymphocyte subpopulations derangement in Turner's syndrome. Journal of Immunogenetics $19818337-344$.

29 al Attas RA, Rahi AH \& Ahmed E. Common variable immunodeficiency with CD4 + T lymphocytopenia and overproduction of soluble IL-2 receptor associated with Turner's syndrome and dorsal kyphoscoliosis. Journal of Clinical Pathology $1997 \mathbf{5 0}$ 876-879.

30 Robson SC \& Potter PC. Common variable immunodeficiency in association with Turner's syndrome. Journal of Clinical and Laboratory Immunology 199032 143-146.

31 Hochberg Z, Aviram M, Rubin D \& Pollack S. Decreased sensitivity to insulin-like growth factor I in Turner's syndrome: a study of monocytes and T lymphocytes. European Journal of Clinical Investigation $199727543-547$.

32 Kurabayashi T, Yasuda M, Fujimaki T, Yamamoto Y, Oda K \& Tanaka K. Effect of hormone replacement therapy on spinal bone mineral density and $\mathrm{T}$ lymphocyte subsets in premature ovarian failure and Turner's syndrome. International Journal of Gynaecology and Obstetrics 199342 25-31.

33 Gupta S, Chiplunkar S, Gupta A \& Gollapudi S. Increased spontaneous tumor necrosis factor receptor- and CD95 (Fas)-mediated apoptosis in cord blood T-cell subsets from Turner's syndrome. Genes and Immunity $2003 \mathbf{4} 239-243$.

34 Paananen R, Sormunen R, Glumoff V, van Eijk M \& Hallman M. Surfactant proteins A and D in Eustachian tube epithelium. American Journal of Physiology. Lung Cellular and Molecular Physiology 2001281 L660-L667.

35 Quigley CA, Crowe BJ, Anglin DG \& Chipman JJ. Growth hormone and low dose estrogen in Turner syndrome: results of a United States multi-center trial to near-final height. Journal of Clinical Endocrinology and Metabolism 200287 2033-2041.

36 Takala J, Ruokonen E, Webster NR, Nielsen MS, Zandstra DF, Vundelinckx G \& Hinds CJ. Increased mortality associated with growth hormone treatment in critically ill adults. New England Journal of Medicine 1999 341 785-792.

37 Hansen TK, Thiel S, Wouters PJ, Christiansen JS \& Van den BG. Intensive insulin therapy exerts anti inflammatory effects in critically ill patients and counteracts the adverse effect of low mannose-binding lectin levels. Journal of Clinical Endocrinology and Metabolism $2003 \mathbf{8 8} 1082-1088$.

38 Van den Berge G, Wouters P, Weekers F, Verwaest C, Bruyninckx F, Schetz M, Vlasselaers D, Ferdinande P, Lauwers P \& Bouillon R. Intensive insulin therapy in the critically ill patients. New England Journal of Medicine 2001345 1359-1367.

39 Haddad JG. Plasma vitamin D-binding protein (Gc-globulin): multiple tasks. Journal of Steroid Biochemistry and Molecular Biology $199553579-582$.

40 Norman AW, Bishop JE, Collins ED, Seo EG, Satchell DP, Dormanen MC, Zanello SB, Farach-Carson MC, Bouillon R \& Okamura WH. Differing shapes of 1-alpha,25-dihydroxyvitamin D3 function as ligands for the D-binding protein, nuclear receptor 
and membrane receptor: a status report. Journal of Steroid Biochemistry and Molecular Biology 199656 13-22.

41 Berger D \& Beger HG. Evidence for endotoxin binding capacity of human Gc-globulin and transferrin. Clinica Chimica Acta 1987 $163289-299$.

42 Yamamoto N \& Kumashiro R. Conversion of vitamin D3 binding protein (group-specific component) to a macrophage-activating factor by the stepwise action of betagalactosidase of B cells and sialidase of T cells. Journal of Immunology $19931512794-2802$.

43 van Hoof HJ, de Sevaux RG, Van Baelen H, Swinkels LM, Klipping C, Ross HA \& Sweep CG. Relationship between free and total 1,25-dihydroxyvitamin D in conditions of modified binding. European Journal of Endocrinology $2001144391-396$.

44 Vihervuori E, Sipila I \& Siimes MA. Increases in hemoglobin concentration and iron needs in response to growth hormone treatment. Journal of Pediatrics $1994125242-245$.

Received 9 June 2003

Accepted 10 November 2003 